\title{
The Effect of Insurance Status on the Rate of Surgery Following a Meniscal Tear
}

\author{
Kenneth R. Gundle, BA; and Arun J. Ramappa, MD \\ Beth Israel Deaconess Medical Center
}

\section{INTRODUCTION}

Barriers of access, availability, and cost prevent the benefits of advancing medical science from reducing morbidity and mortality in many patients. In 2005, 46.6 million people in the United States were without health insurance coverage. ${ }^{1}$ Uninsured Americans have greater unmet health needs, and are more likely to delay seeking treatment due to cost. $^{2}$ A growing and substantial literature suggests that lacking health insurance has adverse effects on health and the utilization of medical care. ${ }^{3}$

Following orthopaedic injury to the lower extremity, such as a meniscal tear, a decision must be made between conservative and operative treatment. This is another point in the course of clinical care that could differ based on insurance status. The purpose of this study was to determine if insurance status affects patients' surgical treatment following a diagnosis of meniscal tear. Following this initial work, we plan to expand our research to include other orthopaedic interventions.

\section{METHODS}

We conducted a retrospective records review for patients diagnosed with a meniscal tear between January 8, 2004 and April 26, 2006. The patients' insurance status and demographic information was recorded, as was whether the patient underwent arthroscopic surgery.

The primary endpoint was whether the patient had an arthroscopic surgery within five months of an office visit for a meniscal tear. Subjects were grouped by insurance status into six categories: private insurance, self-pay, free care, MassHealth, Medicare, and workers compensation. The proportion of patients in each insurance category who undergo surgery was tested for significant difference using the chi-squared test.

Kenneth R. Gundle, BA, Department of Orthopaedics, BIDMC Arun Ramappa MD, Instructor, Harvard Medical School

Address correspondence to:

Department of Orthopedic Surgery Beth Israel Deaconness Medical Center 330 Brookline Avenue, Stoneman 10 Boston, MA 02215

\begin{tabular}{|c|c|c|c|c|}
\hline $\begin{array}{l}\text { Insurance } \\
\text { Category }\end{array}$ & $\mathrm{n}$ & Surgery & No Surgery & $\begin{array}{l}\text { Surgical } \\
\text { Rate }\end{array}$ \\
\hline Private & 670 & 265 & 405 & 40 \\
\hline Free care & 58 & 26 & 32 & 45 \\
\hline Self-pay & 42 & 8 & 34 & $19 *$ \\
\hline MassHealth & 115 & 59 & 56 & $51^{*}$ \\
\hline Medicare & 200 & 66 & 134 & 33 \\
\hline Workers Comp & 42 & 22 & 20 & 52 \\
\hline Total & 1127 & 446 & 681 & 40 \\
\hline
\end{tabular}

Table 1: Patients were separated into six insurance categories, and as to whether surgery was performed following a diagnosis of meniscal tear. * - Indicates a significant difference $(p<0.05)$ when compared to private insurance.

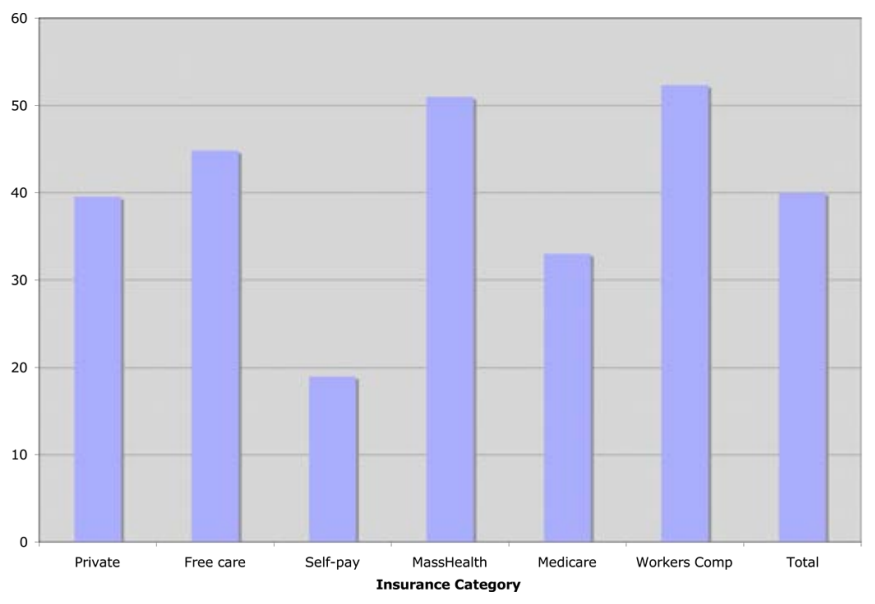

Figure 1: Percentage of patients who received surgical treatment following a diagnosis of meniscal tear, by insurance category.

\section{RESULTS}

Out of the 1127 patients who were included in the analysis, $446(40 \%)$ underwent arthroscopic knee surgery for their meniscal tear (see Table 1). As shown in Figure 1, the percentage of patients treated surgically ranged from $19 \%$ in the selfpay category to $52 \%$ for patients with workers compensation. For the chi-square analysis, each insurance category was compared to private insurance to test for significant differences in the proportion of patients who received surgery. The self-pay category had a slower rate of surgical treatment compared to private insurance, while higher rates were seen in MassHealth patients $(\mathrm{p}<0.05)$. 


\section{DISCUSSION}

These are initial results from our ongoing study of the effect of insurance status on the rates of surgery following a meniscal tear. With patients separated into six general categories of insurance, we found significant differences in the proportion of patients who received surgical treatment. Patients without any form of public or private insurance (i.e. self-pay) underwent surgery less than half as often as private insurance patients in this sample $(\mathrm{p}<0.05)$. This result agrees with prior studies showing uninsured patients altering or foregoing certain treatments due to an inability to pay. ${ }^{4}$

Different insurance categories have variable reimbursements to surgeons, and the potential exists for this to influence clinical decision-making. In this study, the free care category had no significant difference in the rate of surgery, despite the lack of direct compensation to surgeons for these patients. Also, the relatively high reimbursement from workers compensation did not result in a vastly elevated difference in the rate of surgery, though this may be due to the sample size. MassHealth, which has modest reimbursement, was the only category with a significantly higher proportion of surgical patients $(\mathrm{p}<0.05)$. These findings argue against a financial motivation on the part of the surgeon in influencing clinical decisions.

Important questions remain about potential confounding by age, severity of illness, and other factors that may influence these results. In addition to expanding this analysis, we plan to assess the effect of insurance status on the rates of orthopaedic surgery for other conditions. These results may become a baseline for researching changes in the rates of orthopaedic surgery as insurance reforms in Massachusetts are implemented.

\section{References}

\footnotetext{
Income, Poverty, and Health Insurance Coverage in the United States: 2005. http://www.census. $00 \mathrm{v} / \mathrm{hhes} / \mathrm{www} / \mathrm{hlthins/hlthin05.html.} \mathrm{Accessed} \mathrm{June} \mathrm{29,} \mathrm{2007.}$ Ayanian JZ, Weissman JS, Schneider EC, Ginsburg JA, Zaslavsky AM. Unmet health needs of uninsured adults in the united states. JAMA. 2000;284:2061-2069. Institute of Medicine. Care Without Coverage. Washington, DC: National Academy Press; 2002.

Weissman JS, Stern R, Fielding SL, Epstein AM. Delayed access to health care: risk factors, reasons, and consequences. Ann Intern Med. 1991;114:325-331. Steinbrook, R. Health care reform in Massachusetts - a work in progress. N Engl J Med. 2006;354(20):2095-8.
} 